\title{
O Ensino Superior Artístico de Belas Artes: perspetivas e dilemas
}

\section{Current Artistic Higher Education: perspectives and dilemmas}

Mónica Oliveira ${ }^{1}$ 


\section{Resumo}

Pensar o ensino superior artístico de belas artes atualmente é pensar as circunstâncias do contexto ecológico da formação dos estudantes e também na forma de trabalhar dos professores, tendo em conta as evidências resultantes quer do meio artístico, quer da sociedade atual, quer dos pressupostos enumerados pela política educativa vigente. Assim este artigo pretende refletir sobre as perspetivas de ensino-aprendizagem no ensino superior artístico de belas artes, através da perceção dos docentes, perspetivando - futuro.Este trabalho privilegia uma abordagem metodológica mista cujos objetivos passam por: compreender como os professores se percebem enquanto profissionais; que dilemas vivem atualmente e como perspetivam a formação no ensino superior artístico de belas artes. As conclusões emergentes do estudo evidenciam a necessidade de uma reforma curricular ensino superior artístico de belas artes, visando a inovação dos processos de formação.

Palavras chave: ensino superior de belas artes; ensino-aprendizagem; identidade profissional docente; perspetivas; dilemas.

\section{Abstract}

Think of artistic higher education in fine arts today is to think about the circumstances of the ecological context of student training and also about the way teachers work, taking into account the evidence resulting from both the artistic environment and current society and from the assumptions enumerated by educational policy. Thus this article intends to reflect on the perspectives of teachinglearning in the artistic higher education of fine arts, through the perception of the teachers, prospecting the future. This work focuses on a mixed methodological approach whose objectives are: understand how teachers perceive themselves as professionals; what dilemmas they live in nowadays and how they prospect the formation in the artistic higher education of fine arts. The emerging conclusions of the study highlight the need for curricular reform in higher artistic education, aiming at the innovation of training processes.

Keywords: higher education of fine arts; teaching and learning; professional teacher identity; perspectives; dilemmas

ISSN: $2175-2346$ 


\section{Introdução}

A chegada do século XXI emerge num contexto de um mundo globalizado, de uma nova sociedade a que se convencionou chamar de sociedade da informação e do conhecimento. Neste contexto também as conceções de arte, sustentadas pela pós-modernidade, provocaram grandes mudanças no contexto social e abriram um espaço de questionamento sobre o ensino da arte que implica novas formas de pensar e de produzir a obra artística.

E estas mudanças, assim como as alterações do contexto político, económico e social vigente no espaço europeu, pressupõem alterações nas instituições de ensino superior artístico que espelham o contexto atualmente vivido. Mais, as alterações decorrentes da implementação da Declaração de Bolonha no Ensino Superior Artístico têm vindo a proporcionar um grande debate na comunidade académica em relação à estruturação dos novos programas de estudo, exigindo uma profunda mudança de mentalidades por parte de instituições, docentes e estudantes.

Nesta transição paradigmática cuja atmosfera social é assinalada por crise, incerteza:" Há um desassossego no ar. Temos a sensação de estar na orla do tempo, entre um presente quase a terminar e um futuro que ainda não nasceu" (SANTOS, 2000, p.41). Tendo como pano de fundo estas alterações, decorre, a necessidade de (re)pensar o ensino superior artístico de belas artes atualmente baseada na análise da configuração identitária profissional do professor de ensino superior artístico e na sua imagem socioprofissional no contexto das transformações ocorridas atualmente, perspetivando um futuro já que "sem eles é completamente absurdo pensar em reformas ou em mudanças de prioridades, metas ou objetivos." (EÇA, 2010, p. 128)

Pensar no ensino superior artístico de belas artes hoje é pensar nos novos desafios e novas exigências, em que valores e práticas em vigor são equacionados, em que mitos e verdades são colocados em causa. E desta problemática emergem algumas questões: Como se caracteriza a docência no ensino superior artístico? Qual a imagem que o professor tem de si mesmo enquanto profissional? Que dilemas vivem atualmente os professores? Que perspetivas para o ensino superior artístico? Qual o perfil profissional do professor do ensino superior artístico? Este estudo pretende pensar ensino superior artístico na atualidade através destas e outras questões, sem a pretensão de estancar o assunto dada a amplitude e complexidade do mesmo.

\section{Docência no Contexto de Ensino Superior Artístico de Belas Artes - Conceções e Dilemas}

A conceção da docência de ensino superior como atividade complexa, exigindo uma multiplicidade de saberes, competências e atitudes, é compreendida como uma prática social concreta, dinâmica, multidimensional, interativa, sempre inédita e imprevisível, bem como um processo que sofre influências de aspetos económicos, técnicos, culturais, éticos, políticos, institucionais, afetivos e estéticos. A dimensão da docência, pela sua natureza artística, complexa, aberta, dinâmica, imprevisível 
e não linear, é dificilmente manipulável e garante, em certa medida, que possa ter um impacto individual e contextual imprevisível. Esta situação joga contra qualquer intenção controladora, a favor da liberdade individual.

Mas desta dinâmica de contextos em mudanças, surgem também dilemas contemporâneos da docência que se inserem num contexto onde estão presentes questões contraditórias, ambivalentes, que requerem reflexões e ações a partir da significação social da profissão docente, assim como de uma constante revisão nos seus movimentos, possibilidades e limitações. O uso do termo "dilemas" deve ser empregado, conforme Miguel Zabalza afirma, "diante de questões que não têm solução linear e única" (2004, p.179). A adoção do termo neste estudo está relacionada com o entendimento de situações que na docência universitária, por vezes, podem configurar-se como complexas, dicotômicas ou tangenciais.

Face à extensão do conceito, este estudo centrar-se-á apenas na identidade profissional do professor e na complexidade do ensino e da aprendizagem no ensino superior artístico.

\section{A identidade profissional do professor}

A sociedade que se desenha na contemporaneidade, em concordância com as mudanças ocorridas no mundo do trabalho e as políticas de educação superior, vem traçando uma nova forma organizacional e funcional para a educação, um novo papel educacional e, em consequência, um novo papel do docente.

O professor é hoje posto à prova por diferentes representações sociais que o pressionam oscilando entre a construção, desconstrução e reconstrução da sua identidade. Sendo assim, a sua imagem vai-se modificando uma vez que "essa identidade é o reflexo de contingências externas" (BERNSTEIN, 2000, p. 42) e internas construída na inter-relação das dimensões pessoal e profissional, em que a dimensão pessoal do professor se reconhece, formando-se e transformando-se em interação com grupos, fundamentando num esforço constante de reflexividade crítica sobre a prática e a construção de uma identidade pessoal, que excede a dimensão e acumulação de conhecimentos. Dito de outro modo, a identidade profissional docente pode ser entendida como uma construção social assinalada por diversos fatores como a nossa história de vida, as condições objetivas de trabalho académico e o imaginário que permeia a profissão académica que, ao interagirem entre si, têm como resultado uma série de representações deles próprios e das funções que exercem.

Nesta conjuntura, sucessivamente alterada pela reestruturação dos aspetos concetuais e organizacionais no ensino superior, em que se clama pela qualidade na formação de nível superior, verifica-se que, de um modo geral, o professor surge agora sobrecarregado de tarefas. Enquanto atores privilegiados de mudanças diversas "em constante aceleração a nível mundial, os docentes vêem-se obrigados a uma corrida contra o tempo, em que são chamados a responder a um conjunto cada vez mais diversificado e complexo de solicitações" (AZEVEDO e GONÇALVES, 2011, p.215). 
Dada a multiplicidade de funções académicas, e administrativas, Mancebo afirma que: "O professor ideal agora é um hibrido de cientista e corretor de valores. Grande parte do seu tempo deve ser dedicado a preencher relatórios, alimentar estatistas, levantar verbas e promover a visibilidade para si e para o seu departamento (...)" (2007, p.77).

A modificação é inevitável e inerente ao tempo em que vivemos. Todavia, o ritmo do movimento parece estar cada vez mais acelerado e arrasta consigo desafios de maior complexidade. Mas nunca deveremos esquecer que são os professores os motores do avanço ou recuo na educação artística superior. Como afirma Zabalza: "Nenhuma inovação é pensável à margem daqueles que a têm de realizar: os professores transformam-se sempre nos mediadores e agentes básicos das inovações das universidades" (2004, p.11).

O processo de mudança, no qual a docência no ensino superior artístico tem um papel preponderante, exige um novo perfil de professor e a ampliação das suas competências.

\section{Ensino-Aprendizagem: um caminho a trilhar}

Considerando a conceção da docência na sua dimensão relativa ao ensino e a aprendizagem para a escola de belas artes do século XXI, o presente texto não pretende ser fechado, mas questionar algumas das que são as mais prementes linhas de atuação que devem fazer parte da arquitetura do ensino superior artístico.

Nesta perspetiva a educação do futuro necessita "dominar" a complexidade do global, ou seja, perceber que o todo tem qualidades ou propriedades que não são encontradas na unidade isolada que, por vezes, se descaracteriza quando separada do todo. É preciso efetivamente recompor o todo para conhecer as partes (Morin, 2006). O ensino superior artístico de belas artes atual não pode promover saberes divididos, compartimentados, pois assim tornam-se inadequados às necessidades da realidade. Ao contrário, ela deve articular os problemas multidisciplinares, transversais, multidimensionais, transnacionais e planetários que estamos a viver. Daí ser necessário levar em consideração a interdisciplinaridade dos conteúdos, contextualizando e globalizando o conhecimento.

É preciso investir na junção dos conhecimentos dispersos e compartimentados, considerar o contexto, investir na multidimensionalidade e complexidade humana. Morin (2006) defende a teoria da inteligência geral pois a inteligência parcelada, compartimentada e reducionista é uma inteligência cega tornando-se inconsciente e irresponsável. Torna a visão do mundo fragmentada, subdivide os problemas, separa o que está unido, torna unidimensional o multidimensional rompe a complexidade do mundo. Assim, o ensino tem de evitar disciplinas hiperespecializadas que impedem a perceção do global e fragmentam o conhecimento, dissolvendo a essência. A interligação dos saberes é o caminho viável para a construção do conhecimento global e a inclusão de valores que permitirá a formação integral do cidadão do século XXI (Morin, 2006). 
Outro aspeto a considerar no ensino superior artístico de belas artes é a articulação entre teoria e prática como elementos fundamentais e indissociáveis, pois toda a aprendizagem está sujeita a um conhecimento e à sua experimentação. No entanto, a valorização teórica, em detrimento da componente prática, é um modelo que, segundo Schön (2000), gera pouca aplicabilidade e compreensão dos problemas do dia-dia.

Para colmatar tais lacunas, realça-se a importância dos professores desenvolverem outras qualidades e saberes que não só os teóricos e específicos, mas também aqueles referentes ao "talento artístico", gerando seres humanos mais intuitivos, criativos, espontâneos e perspicazes.

O ensino superior artístico de belas artes atual deve desenhar uma nova proposta educacional que contemple uma forte componente prática, onde os alunos aprendem fazendo, ou seja, toda a teoria deve ter transportada e sustentar a sua prática. Esta ideia é corroborada por Donald Schön (2000), quando entende que o aluno deve ser instruído a fazer e desta forma aprender. $O$ aluno deve poder perceber e tornar inteligível, por si próprio e à sua maneira, "as relações entre meios e métodos empregados e resultados atingidos. Ninguém mais pode ver por ele, e ele não poderá ver apenas falando-se a ele, mesmo que o falar correto possa guiar o seu olhar e ajudá-lo a ver o que ele precisa ver". (SCHON, 2000, p. 25).

Desta forma, a prática artística, através de uma reflexão-ação (Schön, 2000) ajuda não apenas a dominar conteúdos e teorias, mas também a utilizá-los em soluções de problemas e conflitos. Como afirma Perrenoud, "Isso pressupõe uma pedagogia ativa, cooperativa, onde se deve propor trabalhar por projetos e problemas, e desafios que incitem os alunos a mobilizar os seus conhecimentos e a completálos" (PERRENOUD, 2000, p.183). A problematização, assunto/metodologia central à educação artística, deve favorecer a aptidão natural da mente em formular e resolver problemas essenciais e, de forma articulada, estimular o uso da inteligência geral e da criatividade para responder às mais diversas situações de forma espontânea, através da capacidade de improvisação, da inovação, estando os alunos preparados para fazer face à originalidade e autonomia do pensamento criativo.

E este é outro aspeto fundamental numa escola de artes do século XXI: um professor não pode ignorar que a criatividade é um princípio básico da educação e que ela deve ter lugar de destaque nas intenções pedagógicas (Martins, 1998). Esse pensamento criador caracteriza-se por ser um processo exploratório, recompensa de uma aventura, por uma busca pelo desconhecido. Michalko (2002) constata que pensar criativamente é ver o que ninguém mais vê, valendo-se de estratégias de saber ver e fazer com que o seu pensamento se torne visível; é pensar naquilo que ninguém pensou que envolve fluidez de ideias, fazer novas combinações, articular o que não está articulado, pesquisar outros mundos. A pessoa que se quer tornar criativa, não pode trilhar o mesmo caminho dos outros, tem de descobrir o seu caminho, tem de ser um não-conformista. Os alunos precisam compreender que, para um completo processo criativo devem, não somente ter em consideração os saberes veiculados pelos seus professores, mas, para que este processo se efetive, ter a habilidade de fazer algo de 
uma maneira diferente, ultrapassando os moldes do convencional. Há que aprender a imaginar o objeto e simultaneamente inventar a sua construção. De contrário a escola torna-se um lugar de indefinível adestramento do que chamam criatividade, centrada apenas no manuseamento de materiais e métodos reprodutivos. Esta ideia entronca na necessidade dos alunos serem estimulados a procurarem sempre novas informações e experiências através de uma investigação constante, possibilitando o surgimento e o aprimoramento de uma postura crítica em relação às artes e à sociedade com a qual a escola deve estar intimamente relacionada, transformando o processo de ensino-aprendizagem num processo de "diálogo" com a realidade social, trazendo a participação, a interação, o debate e partilha de saberes, experiências, significações e representações como elo que envolve alunos, professores e a sociedade em que estamos inseridos. Esta ligação à comunidade é fundamental para que o aluno possa ser um bom crítico das relações que cercam o quotidiano do ser humano, seja ele sociocultural, económico, político ou outros, assumindo o seu papel como cidadão e parte da sociedade.

A questão central que deve envolver uma (re)concetualização do ensino superior artístico atual é a unicidade, a interligação dos conhecimentos numa busca incessante de novas respostas a diferentes desafios para a compreensão da complexidade do mundo e uma melhor atuação. O discurso é de fácil compreensão mas, na prática, de difícil operacionalização. Assim, pretende-se que seja formado, não somente um profissional, mas também um cidadão que irá compreender e conceber/desenhar/ produzir projetos artísticos e culturais com responsabilidade social que possibilitem tornar o imaginado num futuro concreto.

\section{Metodologia do estudo}

Dados os novos desafios que se colocam, conhecer o pensamento do professor do ensino superior artístico de belas artes sobre a sua prática docente é de primordial importância. O estudo que damos conta e se insere num projeto mais extenso é meramente exploratório e para a sua concretização utilizou-se uma metodologia de investigação de carácter misto, que combina aspetos de dois paradigmas de investigação, quantitativo e qualitativo, através do desenvolvimento de uma linguagem externa de descrição que resulta de uma dialética constante entre os conceitos fornecidos pela teoria e os dados empíricos "observáveis" no contexto em análise.

Este estudo visa conhecer como um grupo de docentes de ensino superior artístico de belas artes se situa face às seguintes questões: Caracterização da docência no ensino superior artístico de belas artes; os dilemas da docência atual; a perceção dos docentes face à sua identidade profissional; as mudanças necessárias para uma nova escola de belas artes do século XXI.

O estudo abrangeu 40 professores de ensino superior artístico a lecionar em Portugal, de áreas disciplinares diferentes e com uma experiência profissional igual ou superior a 7 anos.

A técnica de recolha de dados usada foi a entrevista semidiretiva. O guião, 
orientado pelos eixos temáticos correspondentes às questões antes referidas, era suficientemente aberto para permitir a expressão livre dos entrevistados. Para o tratamento dos dados usou-se a análise categorial de conteúdo. Cada entrevista espelha o cruzamento e a sobreposição de referências culturais e experiências diversas onde convicções, dúvidas e sentimentos parecem, por vezes, ultrapassar as lógicas académicas. As mesmas foram analisadas por unidades de sentido que, por comparação semântica, originaram indicadores, categorias e subcategorias. Procedeu-se à análise descritiva na qual se evidencia o conjunto de significados presentes em cada uma das unidades de análise, numa abordagem plural, fazendo uso de citações diretas dos dados originais.

Este artigo limita-se a uma síntese baseada na categorização geral encontrada, para a qual o discurso dos entrevistados concorre de formas distintas. As diferenças individuais situam-se sobretudo ao nível das subcategorias e dos indicadores que as definem.

\section{Análise de dados}

\section{Perfil dos entrevistados}

A tabela seguinte apresenta de forma resumida o perfil dos entrevistados. Como se pode verificar os dados revelam que a amostra possui uma vivência na docência no ensino superior artístico e, portanto, possuem uma visão sobre a identidade profissional em relação à conjuntura onde está inserido.

Tabela 1. Perfil dos entrevistados

\begin{tabular}{|c|c|c|c|}
\hline Faixa etária & Grau académico & $\begin{array}{l}\text { Sistema de Ensino } \\
\text { onde lecionam }\end{array}$ & Anos de lecionação \\
\hline $\begin{array}{c}60 \% \text { dos } \\
\text { professores } \\
\text { encontra-se entre } \\
\text { os } 42 \text { e } 55 \text { anos e } \\
40 \% \text { entre os } 56 \text { e } \\
60 \text { anos. }\end{array}$ & $\begin{array}{l}60 \% \text { têm o grau } \\
\text { de doutor e } \\
40 \% \text { o grau de } \\
\text { mestre, embora } \\
\text { estes últimos } \\
\text { se encontrem } \\
\text { a finalizar o } \\
\text { doutoramento. }\end{array}$ & $\begin{array}{c}100 \% \text { dos } \\
\text { professores } \\
\text { lecionam lecionam } \\
\text { na universidade. }\end{array}$ & $\begin{array}{c}\text { Todos lecionam } \\
\text { há mais de } 7 \text { anos, } \\
80 \% \text { no intervalo } \\
\text { entre os } 8 \text { e os } 25 \\
\text { anos e } 20 \% \text { há } 30 \\
\text { anos. }\end{array}$ \\
\hline
\end{tabular}

Quanto ao número de horas de trabalho, todos têm um contrato de 35 horas de trabalho semanal variando a distribuição de horas alocadas à prática letiva e não letiva. O intervalo das horas letivas oscila em 70\% dos entrevistados entre as 12 e 18 horas de aulas e os restantes $30 \%$ no intervalo entre as 9 e 10 horas de aulas. Não foi possível quantificar o número de horas não letivas pelas tarefas que cada docente desempenha pois estas variam, de acordo com os entrevistados, com as necessidades 
da instituição. No entanto, foram elencadas várias tarefas desempenhadas nessas horas, tais como acompanhamento de alunos, investigação, preparação de aulas, cargos de coordenação e gestão, participação em comissões de trabalho, em Conselho Pedagógico, em Conselho Científico e em diversas reuniões, tarefas estas que $80 \%$ dos professores afirmam ultrapassar largamente o número de horas estipulado na distribuição do serviço docente. Face à diversidade de atividades, percebe-se que o professor de ensino superior de belas artes tem de ser um profissional múltiplo, ou seja, deve ser simultaneamente um técnico e especialista na área de trabalho que ensina, deve ser investigador numa área de conhecimento, além de um administrador e coordenador de projetos, de grupos de trabalho e órgãos da estrutura administrativa universitária cuja ideia é subscrita por Sílvio Botomé (1996). Esta intensificação do trabalho docente, que envolve uma multiplicidade de funções e atividades é corroborada por Brandão \& Lelis, (2003). Cada vez mais novas funções lhe são acometidas e mais complexo se torna o seu exercício profissional (Zabalza, 2004).

Todos os docentes lecionam em licenciaturas, 60\% lecionam também em mestrados e $40 \%$ em doutoramentos. Observa-se ainda que $90 \%$ lecionam várias unidades curriculares (UC) e $10 \%$ lecionam apenas uma unidade curricular.

\section{Imagem da docência no Ensino Superior Artístico na atualidade}

As conceções da docência expressas pelos entrevistados indicam que as mesmas envolvem um processo de construção que é marcado pela qualidade da formação académica e estruturação do curso para a construção do perfil profissional do aluno. $80 \%$ dos docentes aponta a questão da Reforma de Bolonha, mais concretamente o plano de estudo e a diminuição do número de anos de formação, como uma preocupação: "Com o Processo de Bolonha tentamos dar em 3 anos aquilo que dávamos em 4 e 5 anos, é um atropelo contínuo"- Entrevistado 4 (E4); também a falta de transformação de mentalidades que este processo exigia e não se verificou foi um aspeto apontado por $50 \%$ dos entrevistados "os cursos têm vindo a mudar com muita frequência e mudam muito ao sabor das modas, sem haver tempo para perceber e interiorizar tais mudanças"- E7; verifica-se ainda uma "excessiva compartimentação das aprendizagens das unidades curriculares (UC), inerente ao facto de serem semestrais"- E9, o que origina consequências para a formação dos alunos; "o aluno sai de uma UC para outra e não tem tempo para refletir, para amadurecer as ideias, 3 anos não lhes dá para eles ganharem individualidade, consciência"- E6. Por fim, acresce a esta situação o facto da "maioria dos alunos não seguirem para mestrado." - E8.

Outro aspeto destacado pelos entrevistados prende-se com o compromisso dos professores em relação ao conhecimento. Aqui 70\% dos entrevistados destacam que a maioria dos professores demostram ter domínio do conteúdo nas suas áreas de especialidade, no entanto $60 \%$ considera fundamental a atualização desses conhecimentos. Como diz Zabalza (2006), é necessária uma preparação adequada do professor, nomeadamente em relação à atualização de conhecimentos e à 
identificação e organização de materiais específicos apropriados para responder aos objetivos delineados.

Questão que os entrevistados valorizam é a dimensão pedagógica em que $80 \%$ expressam preocupação nesta área apontando alguns fatores que afetam a prática pedagógica: a distribuição de várias unidades curriculares diferentes, de cursos distintos ao mesmo docente, muitas vezes próximas do início da sua lecionação, não permite ao professor aprofundar conhecimentos e ajustar-se à filosofia que subjaz a especificidade do curso, já que muitas vezes não conhece a sua estrutura global:

"Um docente num ano dá aulas a uma determinada UC e no ano seguinte é chamado a dar outra, não permitindo ao professor criar discursos consequentes e especializar-se."- E1; "a quantidade e diversidade de UC que nos exigem obriganos a uma dispersão muito grande, muitas vezes pondo em causa a qualidade do trabalho que podíamos desenvolver."- E3; " Como é possível fazer um bom trabalho com a quantidade de UC que tenho e a diversidade de cursos onde leciono?" - E2.

Ainda relacionada com a dimensão pedagógica, $80 \%$ dos entrevistados apontam a importância da articulação horizontal e vertical do curso para que esteja em consonância com os objetivos do mesmo:

\footnotetext{
"A competitividade não nos ajuda minimamente, as pessoas estão nos seus lugares e defendem-nos com «unhas e dentes» e falam pouco dos problemas que encontram, porque falar deles, é assumir fragilidades" - E5; "não há tempo para falarmos uns com os outros e discutir qual seria a melhor solução para alcançar outro tipo de resultados" - E5; "As pessoas cumprem as suas funções dentro dos seus parâmetros, mas não cumprem num discurso coletivo, numa parametrização em concordância com os outros" - E208.
}

Por último, $30 \%$ dos entrevistados apontou a necessidade do compromisso da escola com as transformações que estão a ocorrer na sociedade atual redefinindo a sua identidade. Esta ideia passa, como afirma Cashin (2003), por uma maior abertura e transparência no ensino e na investigação exigidas pela sociedade.

Porém os entrevistados, afirmam uma realidade diferente:

\begin{abstract}
"A escola de ensino superior artístico de belas artes atual não é uma escola de artes de século XXI, tem um formato antigo, completamente desatualizado que serve o esquema corporativista mas não responde às necessidades do século XXI" - E8; "sinto que não há projeto de escola, ele não vem da direção, não vem das áreas científicas, não vem da universidade." - E300; "se observamos a história da arte, percebemos que sempre que aparecia uma nova tecnologia na sociedade, surgiam novas formas de arte. Temos de perceber os avanços tecnológicos e a arte tem de (re)produzir esses esquemas tecnológicos" - E220.
\end{abstract}

\title{
A imagem que o docente tem de si próprio no seu desempenho profissional
}

A auto imagem, de acordo com Mosquera e Stobaus (2006), é mais o (re) conhecimento que fazemos de nós mesmos, como sentimos as nossas potencialidades, sentimentos, atitudes e ideias. Nesse sentido, a auto imagem positiva evidenciada por 
90\% dos docentes mobiliza-os no agir profissional, dando suporte para enfrentar as vivências quotidianas no ensino superior artístico. Há uma concordância com um comprometimento no exercício das suas funções de ensino e sentem que são bons orientadores e estão na educação por missão. Estes entrevistados apontam um conjunto de características que se centram na comunicação, na aproximação, na flexibilização e na responsabilidade: "Sou uma pessoa responsável, entusiasmada com o meu trabalho, preocupo-me com a atualização dos conteúdos" - E205; "tento ser o mais aberto possível, o mais afável possível o mais comunicativo possível" E71. 70\% dos professores afirmam que a sua forma de ensinar não assenta apenas na transmissão de conhecimentos, mas no acompanhamento de projetos enquanto tutores de acordo com os diferentes grupos de estudantes:-“Procuro a mediação do conhecimento pelo diálogo, debate, tendo em consideração os alunos que tenho na sala." - E143. Esta imagem docente relaciona-se com as competências pedagógicas do professor, definidas por Shulman (1987), mais concretamente: o conhecimento dos conteúdos relacionados com o seu domínio científico; o conhecimento pedagógico relativamente às formas de transmitir eficaz e adequadamente os conteúdos; os conhecimentos sobre o processo de aprendizagem dos alunos; os conhecimentos sobre como ensinar em diferentes contextos, a grandes e pequenos grupos; os conhecimentos relacionados com o desenho e o desenvolvimento curricular.

Paralelamente a esta imagem positiva, $80 \%$ assumem algum desconforto no seu desempenho profissional, quer de índole pedagógica, institucional ou ainda com o contexto social vivido atualmente:

\begin{abstract}
"Continuo a manter uma auto imagem positiva, mas com muitas angústias e ameaças: a crescente imposição da obrigatoriedade dos papers, a necessidade constante de flexibilização em termos da lecionação de novas UC, a incerteza quanto ao futuro" - E87; " Eu sou bastante empenhada e exigente, mas nos últimos tempos sinto-me muito pouco gratificada pelo trabalho que desenvolvo e esta situação deve-se ao desinteresse dos alunos pelas UC." - E71; "não podemos fazer mais porque não temos as infraestruturas e equipamentos necessários para o desenvolvimento das práticas artísticas." - E166.
\end{abstract}

\title{
Dilemas do desempenho profissional do docente
}

As entrevistas evidenciaram dilemas que podem ser caracterizados em duas dimensões: institucionais e pedagógicos.

No que concerne aos dilemas institucionais, evidenciam-se nos depoimentos os dilemas indicativos ao contexto universitário e os seus reflexos no quotidiano da docência. $80 \%$ dos docentes aponta como uma das principais preocupações a precariedade das infraestruturas e equipamento de trabalho pedagógico. Os extratos seguintes documentam essa oposição:

\footnotetext{
"falta de espaços/instalações para o desenvolvimento das práticas artísticas" - E92; "Espaços desconfortáveis, frios, não existe material de apoio" - E98; "espaços sem iluminação condigna, sem infraestruturas que põem em causa a formação."
} 
- E50; “A falta de recursos bibliográficos, materiais e equipamentos tecnológicos que são necessários à prática artística compromete a formação artística.” - E27.

Outro dos grandes constrangimentos sentidos por $70 \%$ dos entrevistados prendese com as restrições financeiras e com o grande aumento do número de alunos por turma o que impede o desenvolvimento de métodos de ensino mais consentâneos com uma aprendizagem ativa por parte dos mesmos: "Tenho 80 alunos por turma e é muito difícil eu perceber se o que estou a lecionar está a ser rececionado pela maioria dos alunos" - E11; " Numa aula prática ter 30 alunos é impensável!" - E54.

Aspeto realçado por $50 \%$ dos entrevistados é o que resulta da necessidade de conciliar as atividades de ensino com as administrativas:

\footnotetext{
"O aumento das responsabilidades administrativas e de gestão e a sua grande dificuldade de articulação com as demais funções causam-nos vários problemas. Estas atividades consomem muito tempo e nós não temos preparação para as desempenhar" - E37.
}

De acordo com Zabalza (2004), além das 3 funções tradicionalmente atribuídas aos professores universitários - o ensino, a investigação e o trabalho de extensão à comunidade - há o envolvimento com a administração em diversos setores da instituição e, para além destas, novas funções se agregam, tornando mais complexo o exercício profissional.

Quanto aos dilemas pedagógicos, Miguel Zabalza (2004) afirma que estes dizem respeito ao conjunto de proposições contraditórias que se apresentam ao professor no desenrolar da sua atividade profissional. Esses dilemas são expressos nomeadamente na prática pedagógica do docente. $80 \%$ afirmam a intensificação do trabalho docente com o aumento da carga horária para além das horas estipuladas na distribuição do serviço: aulas, correções de trabalhos, acompanhamento a alunos, reuniões, coordenações, exigências burocráticas e investigação são alguns dos aspetos mais evidenciados.

$80 \%$ do discurso dos professores refere também a falta de iniciativas de carácter grupal e institucional, o que confirma a cultura do individualismo no meio universitário. Os professores referiram que não existe partilha de experiências com colegas, nem discussão dos aspetos científicos e artísticos com os pares e só $10 \%$ referem que, por vezes, no seu grupo disciplinar são discutidas algumas questões pedagógicas, o que reforça uma ausência de uma conceção interdisciplinar.

Para além das questões acima expostas, a falta de preparação dos alunos que chegam ao ensino superior na área artística, fruto da educação básica e secundária facilitada e facilitista, traz uma preocupação acrescida a $60 \%$ dos professores já que "são muito poucos os que vêm com preparação para a discussão, para o debate, para o aprofundamento das questões artísticas." - E45. 40\% dos entrevistados salientam a pouca vocação dos alunos atuais para os cursos de arte. A desmotivação e o desinteresse são algumas das questões apontadas, juntamente com a pouca maturidade característica desta juventude:

\footnotetext{
"os alunos estão pouco convictos do que querem fazer e portanto procuram estas
} 
formações porque lhes parecem fáceis, menos responsáveis e quando se lhes exige determinados conhecimentos eles não conseguem lá chegar!"- E69; "Os alunos não demostram disponibilidade para ouvir os professores. Nós tentamos dar-lhes referências de textos, exposições e nada... Tem de haver da parte dos alunos sede de conhecimento, vontade de arriscar, de explorar." - E21

E neste contexto impõe-se uma questão "contínuo com um nível de exigência de ensino superior, pois estamos a preparar pessoas que vão ter uma grande responsabilidade na sociedade ou estando o ensino facilitado desde a instrução primária, contínuo nesta perspetiva de facilitismo e reduzo o grau de exigência?" E178.

Na sua globalidade os professores sentem que são bons profissionais mas não se sentem satisfeitos com a sua carreira e atualmente evidenciam graves dificuldades em gerirem as frustrações e problemas que lhes aparecem no dia-a-dia. Os professores sofrem a pressão de serem educadores eficazes e reflexivos, artistas, investigadores e ainda contribuírem para a liderança e gestão de serviços na faculdade. $O$ equilíbrio entre estas atividades torna-se difícil, desgastante, interfere com a vida particular de cada um, sendo tarefa quase impossível. Os dilemas apontados pelos entrevistados expressam os desafios a serem superados, assim como as contradições presentes no meio universitário. Como afirma Perrenoud (2000), o momento é de insatisfação generalizada e isto levanta questionamentos e busca de soluções. $O$ ensino superior caminha para uma transformação profunda, mas estas mudanças são lentas e dependem não só da vontade dos professores, mas também da participação da sociedade e principalmente dos seus interlocutores.

\section{Aspetos estruturantes para o ensino superior artístico atual}

$40 \%$ dos entrevistados refere que a construção do ensino superior artístico de belas artes atual deve ter o cuidado de ir desenhando novos caminhos sem perder a sua identidade:

\footnotetext{
"A sua função é ser o garante de uma manutenção de saberes, uma ligação com o passado e aquilo que vão sendo as novas descobertas."- E19; "deve-se partir para a novidade mas tentando equilibrar o que está sedimentado e é passado. Quando isto não acontece é curioso ver que o discurso é tentar ir buscar o que se perdeu e que vai ter de se reinventar do zero." - E100.
}

Estes mesmos docentes afirmam que é preciso ter consciência que existem problemas estruturantes que inibem a possibilidade de construir uma transformação e que passam, sobretudo, pela falta de autonomia científica e pedagógica e a perda de prioridade da educação nas políticas públicas juntamente com a crise financeira. A impossibilidade que o ensino superior tem para fazer uma mudança efetiva e eficaz,

"não depende das escolas, mas depende dos poderes, de quem nos governa, das sensibilidades que têm em relação à área artística e da importância que lhe conferem dentro de uma sociedade." - E83. "Não há autonomia, o poder de decisão das escolas é quase nulo. Se quisermos podemos individualmente fazer pequenas 
revoluções na forma de dar aulas mas, enquanto escola, não temos poder.” - E56. “ São os de fora que decidem o que nós somos e se podemos ser." - E48. "O Estado, a Fundação da Ciência e Tecnologia, as Comissões Internacionais de Avaliação, entre outros, ainda não perceberam as nossas especificidades e tratam-nos com se fossemos um curso de ciências exatas e avaliam-nos da mesma forma." - E97. "Eu gostaria que a avaliação das Escolas de Artes deixasse de ser bitolada pelo modelo científico, sobrepor os critérios da ciência aos critérios da criação, traduz um enorme menosprezo pela arte." - E32.

$80 \%$ afirma que uma escola de belas artes do século XXI deve centrar o seu interesse primordial na prática artística:

"O aluno de artes deve estar bem sediado nos ateliers e aí deve ser capaz de articular todos os saberes em prol da prática." - E49; "os alunos de artes deveriam ir todos os dias ao atelier e não apenas 3 vezes por semana. $\mathrm{O}$ atelier agrega saberes, é um espaço de pensar e não só do fazer, onde o aluno constrói os seus discursos." - E15. "Para quê fazer projetos individuais em cada UC, se é possível fazer um projeto que envolva todas as UC e onde todos os professores possam contribuir para que o trabalho seja de profundidade?" - E28.

Outro aspeto salientado por $70 \%$ dos entrevistados é a formação académica: "Devemos estruturar os cursos em função do que nós queremos que estas pessoas efetivamente aprendam nas diferentes áreas." - E55. Tem de se (re)equacionar a formação artística e definir o perfil profissional que se forma para que os alunos assumam um papel responsável e ativo na sociedade. "Não se admite que um aluno saia da faculdade de medicina sem saber a distinção entre um rim e um pulmão, agora na área artística, pode-se confundir cores, podem até não saber desenhar." - E175.

A redução do número de alunos por turma é alvitrada por $70 \%$ dos entrevistados. Não é possível querer uma formação de qualidade com tantos alunos,

"a desumanização que isso provoca e a falta de empatia que se pode criar com as pessoas prejudica a aprendizagem” - E6; "os alunos são cada vez mais jovens, não em idade, mas em maturidade, não permitindo que se desenvolva um trabalho com grande qualidade." - E88.

A necessidade de uma melhor preparação dos alunos que se candidatam ao ensino superior é apontada por $60 \%$ dos docentes pois, no presente, a falta de formação dos mesmos causa graves entraves para o desenvolvimento do conhecimento da escola de belas artes do século XXI:

"A preparação dos alunos na área artística é praticamente nula desde a sua formação básica." - E22; "eles não conhecem a linguagem elementar das artes, nunca visitaram exposições." - E41; "quando chegam ao ensino superior trazem consigo um conjunto rudimentar de conhecimentos onde não é possível dar continuidade ao processo de aprendizagem sem que o ensino superior artístico tenha de fazer o que o ensino básico não fez." - E53.

O desenvolvimento da investigação é considerado como fulcral para fomentar a aliança entre a educação e o avanço do conhecimento por $70 \%$ dos entrevistados.

"O professor do ensino superior artístico terá que saber articular a investigação 
com a criação, articular o ensino com as constantes mudanças e para isso urge investigar" - E64. No entanto referem que é preciso aclarar o que se entende por investigação em artes. " Quando estou no atelier estou a investigar ou não?” E74. "Se publico artigos, não posso dedicar-me à produção artística, por qual devo optar?" - E82.

Apenas 30\% defende que a escola de belas artes do século XXI tem de estabelecer um compromisso com a sociedade, assumir-se no espaço público da cidade, do país, da Europa,

"mas só podemos sair para o exterior quando estivermos integrados uns com os outros." - E18; "Quando tivermos uma ideia daquilo que queremos ser." - E63. A escola de artes do século XXI "tem de deixar de estar fechada nela própria e passar a ser parte integrante do contexto onde está inserida." - E91.

$E$, por último, um entrevistado assume que o mais importante para a escola de artes do século XXI "é fazer com que as pessoas sejam felizes, acreditando que seremos mais felizes com mais conhecimentos, mais experiências." - E1.

\section{O professor do ensino superior artístico de belas artes atual}

Os professores devem ter uma postura aberta e de auto reflexão pessoal e profissional e, nesse sentido, Marlene Grillo (2001) afirma: "O professor necessita ser um investigador que questiona o seu pensamento e a sua prática, que age reflexivamente no ambiente dinâmico, toma decisões e cria respostas mais adequadas." (p.138).

Relativamente ao desenvolvimento profissional docente, $90 \%$ dos entrevistados indica a importância do perfil do professor que compreende o compromisso profissional, as atitudes e normas de conduta. Consideram que este deve ter uma postura aberta à reflexão e auto reflexão pessoal e profissional que enquadre a prática pedagógica. Esta aproximação do professor à arte dá-se através de uma visão social de discursos alternativos, não estandardizados, nem generalizados. Também $90 \%$ considera que o professor deve ser:

\footnotetext{
"um tutor, que encaminha, abre portas, ínsita a investigação, não interfere diretamente num trabalho artístico mas questiona conceitos, paradigmas estéticos, numa pedagogia ativa que permita ao aluno a construção do conhecimento." E233 e deve "motivar os alunos para a aprendizagem, para o debate, para uma reflexão crítica, para não se limitarem a seguir um discurso, uma prática, mas a serem capazes eles próprios de construírem essa prática." - E42." Por essa razão, "o professor deve provocar, fomentar e alimentar as inquietações de cada um e ajudar a ultrapassar dificuldades." - E72.
}

Para $60 \%$ dos docentes o professor "deve ser simultaneamente artista, que produza, porque só assim é possível transmitir a praxis de um exercício, de uma criação." - E12; outra justificação apontada foi a "necessidade do professor/artista ser um modelo e uma referência para os alunos." - E25.

Outro aspeto salientado por $80 \%$ foi a imprescindibilidade da construção de uma identidade coletiva: "precisamos de saber quem somos, o que queremos fazer enquanto 
grupo, para onde caminhamos" - E62. De acordo com Chopp (2001), os professores devem criar espaços comuns entre eles, entre departamentos até aí separados pelas barreiras dos domínios científicos, onde se possam debater ideias, conhecerem-se melhor, apoiarem-se, criarem sinergias em prol do ensino-aprendizagem.

$60 \%$ consideram relevante a disposição dos docentes para a aquisição de conhecimentos, competências próprias e formação específica. E94 afirma "era importante voltar a estudar inglês, tenho recebido muitos alunos Erasmus e tenho muita dificuldade em comunicar com eles"; por outro lado foi salientado "o conhecimento de aspetos pedagógicos são fundamentais para quem quer ser professor." - E151. Como afirma Formosinho, "A formação contínua tem como finalidade última o aperfeiçoamento pessoal e social de cada professor, numa perspectiva de educação permanente." (1991, p.238), fundamental para transformar o ensino num espaço de troca e de reconstrução de novos conhecimentos.

\section{Considerações finais}

Os resultados confrontam-nos com a evidência de sensibilidades e posturas diferentes que representam apenas algumas possibilidades a considerar para o ensino superior artístico atual. Se a escola de belas artes não é estática e se é impelida a acompanhar e, muitas vezes, antecipar as mudanças sociais, o conceito de professor é um conceito em (re)construção permanente pelos seus profissionais. Reconstrução sempre difícil por implicar a redefinição de ideais interiorizados e a reconfiguração de identidades pessoais e grupais. Reconstrução inquietante, sobretudo em momentos de viragem, em que corresponde tanto à pressão de forças exógenas como endógenas, como parece ser atualmente o caso, face aos dados apurados pelos entrevistados.

Analisando os dados através da sua triangulação, e tendo como alicerces as conceções atuais da docência, os seus dilemas e os aspetos estruturantes para o ensino superior artístico atual ventilados pelos entrevistados, percebe-se que muitos dos princípios e valores são comuns à maioria dos professores, nomeadamente:

- A melhoria das condições físicas e materiais. Os entrevistados realçaram que a falta de condições físicas, de materiais e equipamento necessário compromete de modo significativo as práticas artísticas. De acordo com a conceção de ensino artístico, as condições físicas e materiais devem transformar-se em recursos para possibilitar a criatividade, a inovação e a construção de práticas diversificadas. Por essa razão, os espaços e as condições disponíveis têm de ser adaptados e criados para a especificidade deste ensino. A qualidade do ensino artístico de belas artes depende da superação das deficiências estruturais.

- A diminuição de alunos por turma. Pela voz dos entrevistados percebe-se que a maioria se confronta com turmas com um grande número de alunos, quer em UC teóricas, quer em UC práticas, que colocam em causa a qualidade pedagógica. Importa, por isso, que sejam encontradas soluções para ultrapassar esta questão.

- A postura do professor no desenvolvimento de práticas pedagógicas. Os entrevistados consideram que o professor deve ser crítico, reflexivo, criativo, investigador aberto à 
mudança, mostrar-se comprometido com práticas e reflexões artísticas interdisciplinares e com uma educação emancipadora trabalhando em clima colaborativo para os projetos e missões institucionais, com sentido de responsabilidade e compromisso nos diferentes papéis que assume.

- A formação artístico-pedagógica como caminho para a melhoria da docência. As entrevistas reforçam a necessidade de uma maior formação do professor construtor de conhecimento em arte. Com a globalização da concorrência, a aceleração das transformações tecnológicas e os desafios colocados pelo aumento de produtividade e competitividade assentes no conhecimento, entende-se facilmente 0 apelo à intensificação e ao alargamento da participação dos professores em atividades de aprendizagem ao longo da vida, para responder às preocupações decorrentes do mundo do trabalho em contínua evolução. Ele deve aprofundar conhecimentos sobre a realidade artístico-cultural, em diferentes tempos, espaços e proposições.

- O investimento na investigação. Embora os entrevistados falem nela e compreendam a sua importância, eles mencionam-na como algo que lhes é exigido, que é importante para a carreira, mas para a qual não se sentem motivados. A maioria dos entrevistados assegura que esta situação advém do facto de não existir uma cultura de investigação nesta área. O ensino superior artístico atual deve ter como um dos seus aspetos estruturantes a investigação em artes e contribuir para aclarar o que se entende por investigação em artes.

- A construção da identidade de uma escola de belas artes e do professor de ensino artístico. Nas respostas obtidas pelos entrevistados não encontrámos uma ideologia clara que fosse um traço de união entre a classe professoral. Salienta-se a falta de identidade dos professores, da escola de artes, a falta de diálogo entre eles, o jogo de forças e interesses institucionais. Esta situação, como muitos afirmam, advém do processo de transformações profundas a que assistimos, nomeadamente a necessidade da produtividade, a competitividade, $\mathrm{O}$ isolamento académico. Aliás, esta ideia é reiterada pela maioria dos entrevistados, não só quando falam da docência atual, dos seus dilemas, mas também quando os mesmos perspetivam o ensino superior artístico atual. Esta consciência coletiva da necessidade de mudança de paradigma é o princípio orientador da transformação da escola de artes.

- A extensão à comunidade. Os professores entrevistados realçaram a pouca importância da intervenção da escola na sociedade onde está inserida. Embora a considerem fundamental, esta só será possível se houver uma identidade académica. Não há dúvida que o mundo académico deve envolver-se mais com os processos sociais, económicos e culturais. A formação do profissional cidadão é imprescindivel à sua efetiva interação com a sociedade, seja para se situar historicamente, para se identificar culturalmente e/ou para referenciar a sua formação técnica com os problemas que um dia terá que enfrentar.

As possibilidades acima mencionadas pretendem ser consideradas resultados provisórios de um itinerário investigativo que se espera poder ser um convite para a reflexão e o debate académico. Os aspetos negativos apontados pelos entrevistados não se podem considerar uma dimensão perdida, são sim, uma dimensão visível, que terá de ser objeto de reflexões entre professores e instituições para que o ensino superior artístico de belas artes atual trilhe novos caminhos consentâneos com a realidade atual. $O$ desafio para este tipo de ensino é o equilíbrio entre as funções 
básicas de ensino, investigação e serviço e a postura dos diferentes interlocutores com vista a alcançar as metas educacionais para formar especialistas com as competências artísticas apropriadas e, ao mesmo tempo, contribuir para o progresso, extensão e disseminação do conhecimento.

\section{Referências}

AZEVEDO, S., GONÇALVES, I. (2011), Sustentar o desenvolvimento contínuo de professores e estudantes e capacitá-los para os processos de mudança pessoal, interpessoal e institucional. In: GONÇALVES, I. (Org.). Programa de monitorização e tutorado: oito anos a promover a integração e o sucesso académico no IST/ ed. Gabinete de apoio ao tutorado. Lisboa: Instituto Superior Técnico Press, 2011.

BERNSTEIN, B. Pedagogy, symbolic control and identity: theory, research, critique. Lanham, MD: Rowman \& Littlefield, 2000.

BOTOMÉ, S. Pesquisa alienada e ensino alienante. Rio de janeiro: Vozes, 1996.

BRANDÃO, Z. \& LELIS, I. Elites acadêmicas e escolarização dos filhos. Educação e Sociedade. São Paulo. V. 24, n. 83, p. 509-26, agosto 2003.

CASHIN, W. Evaluating college and university teaching: reflections of a practitioner. In: SMART, J. (Ed), Higher Education Handbook of Theory and Research. Dordrecht: Kluwer Academic Publishers, 2003.

CHOPP, R. ; FROST, S. \& JEAN, P. What's old in new again Alternative Strategies for Supporting Faculty. Change: The Magazine of Higher Learning. V. 33, n.6, p. 43-46, 2001 Disponível em: http://www.tandfonline.com/toc/vchn20/33/6?nav=tocList. Acesso em 15 agosto, 2017.

EÇA, T. A Educação Artística e as prioridades educativas do início do século XXI. Revista Iberoamericana de educação, Madrid: Organización de Estados Iberoamericanos para la Educación, la Ciência y la Cultura, n. 52, jan./abr. 2010. Disponível em: http://www. rieoei.org/rie52a07.pdf. Acesso em 1 jan. 2016

FORMOSINHO, J. Formação contínua de professores: Realidades e perspectivas. Aveiro: Universidade de Aveiro, 1991.

GRILLO, M. O lugar da reflexão na construção do conhecimento profissional. In: MOROSINI, M. (Org.). Professor de Ensino Superior: identidade, docência e formação. Brasília: Plano Editora, 2011, p. 75-80.

HALL, S. A identidade cultural na pós-modernidade. Rio de janeiro: DP\&A, 2003.

MANCEBO, D. Trabalho docente: subjetividade, sobre implicação e prazer. Psicologia: Reflexão e Crítica, Rio Grande do Sul: Curso de Pós-Graduação em Psicologia da Universidade Federal, v. 20, n.1, 2007. Disponível em: http://www.redalyc.org/articulo. oa?id=18820110 Acesso em 1 jan. 2016 
MARTINS, M. A urgência da criatividade. Revista Millenium, Viseu: Revista do Instituto Politécnico de Viseu, n. 9, jan. 1998. Disponível em: http://www.ipv.pt/millenium/ pers9_vmtm.htm Acesso em: 1 jan. 21016

MICHALKO, M. Los secretos de los genios de la creatividad. Barcelona: Ed. Gestión, 2002.

MORIN, E. Os sete saberes necessários à educação do futuro. São Paulo: Cortez, 2006.

MOSQUERA, J., STOBAUS, D. Auto-imagem, auto-estima e auto-realização: qualidade de vida na universidade. Revista Psicologia, Saúde \& Doenças, Lisboa: Sociedade Portuguesa de Psicologia da Saúde, v. 7, n.1, p. 83-88, jul. 2006.

PERRENOUD, P. Dez novas competências pra ensinar. Porto Alegre: Artmed editora, 2000.

SANTOS, B. Para um novo senso comum: a ciência, o direito e a política na transição paradigmática. São Paulo: Cortez, 2000.

SCHON, D. Educando o profissional reflexivo: um novo design para o ensino e a aprendizagem. Porto Alegre: Artmed, 2000.

SHULMAN, L. Knowledge and teaching: Foundations of the new reform. Harvard Educational Review. Cambridge, V. 57, n.1, p.1-22, fev.1987.

ZABALZA, M. O ensino universitário: seu cenário e seus protagonistas. Porto Alegre: Artmed, 2004.

ZABALZA, M. Uma nova didática para o ensino universitário - respondendo ao desafio do espaço europeu do Ensino Superior. Porto: Universidade do Porto, 2006. 
